\title{
'WHAT VISION'?: EXPERIENCES OF TEAM MEMBERS IN A COMMUNITY SERVICE FOR ADULTS WITH INTELLECTUAL DISABILITIES
}

\author{
${ }^{*}$ Clare, I.C.H. ${ }^{1,2,3}$, Madden, E.M. ${ }^{4}$, Holland, A.J. ${ }^{1,2}$, Farrington, C.J.T ${ }^{5}$, \\ Whitson, S. ${ }^{6}$, \\ 'Broughton, S. ${ }^{3}$, Lillywhite, A. ${ }^{1,2,3}$, Jones, E. ${ }^{1,2,3}$, Wade, K.A. ${ }^{1,2}$, Redley, M. ${ }^{1,2}$ \\ and Wagner, A.P. ${ }^{1,2}$
}

1 NIHR CLAHRC East of England at Cambridgeshire \& Peterborough NHS Foundation Trust, Cambridge, UK

2 Cambridge Intellectual \& Developmental Disabilities Research Group, Department of Psychiatry, University of Cambridge, Cambridge, UK

3 Cambridgeshire \& Peterborough NHS Foundation Trust

4 Royal College of Physicians, London

5 Cambridge Centre for Health Services Research, Institute of Public Health, University of Cambridge

6 Clinical Psychology Doctorate Training Course, University of Surrey

This is the author manuscript accepted for publication and has undergone full peer review but has not been through the copyediting, typesetting, pagination and proofreading process, which may lead to differences between this version and the Version of Record. Please cite this article as doi: 10.1111/jir.12312

This article is protected by copyright. All rights reserved. 


\section{ABSTRACT}

Background: In the UK, the closure of 'long-stay' hospitals was accompanied by the development of community teams (CTs) to support people with intellectual disabilities (IDs) to live in community settings. The self-reported experiences of staff working in such teams has been neglected.

Methods: Focusing on a single county-wide service, comprising five multi-disciplinary and inter-agency CTs, we measured perceptions among the health care and care management team members of (i) their personal well-being (Maslach Burnout Inventory (MBI) Maslach and Jackson, 1981); (ii) the functioning of their team (Team Climate Inventory (TCl) Anderson and West, 1994) and (iii) organisational commitment to quality and culture (the Quality Implementation Improvement Survey - II (QIIS-II, Shortell et al., 1995, 2000).

Results: Almost three-quarters of the questionnaires were returned (73/101; 72\%). The scores of health care and care managers were very similar: the $\mathrm{MBI}$ scores of more than half the respondents were 'of concern'; (ii) similarly, almost four in ten respondents' scores on the Vision scale were 'of concern'; (iii) the perceived commitment to quality (QIIS-II Part 2) was uncertain; and (iv) the organisational culture (QIIS-II, Part 1) was viewed as primarily hierarchical.

Discussion: The perceived absence of a vision for the service, combined with a dominant culture viewed by its members as strongly focussed on bureaucracy and process, potentially compromises the ability of these CTs to respond proactively to the needs of people with IDs. Given the challenges that changes in legislation, policy, and practice that have taken place since CTs were established, it would be timely to revisit their role and purpose.

This article is protected by copyright. All rights reserved. 


\section{'WHAT VISION'?: SELF-REPORTED EXPERIENCES OF TEAM MEMBERS IN A COMMUNITY SERVICE FOR ADULTS WITH INTELLECTUAL DISABILITIES IN ENGLAND}

\section{Introduction}

In England, as in other parts of the UK, the development of locality-based community teams (CTs) for people with intellectual disabilities (IDs) accompanied, and, indeed, often drove, the closure of the 'long-stay' hospitals (King's Fund,1980; see discussion in Greig and Peck, 1998), and supported an 'ordinary life' for those individuals - the majority - who had always lived in community settings. The task of these CTs was two-fold: (i) to address the limited access of people with IDs to health and/or social care services available to the rest of the population; and (ii) to provide specialist expertise and experience to meet the particular health and social care needs that are associated with an ID (Lindsey, 2002). While there has never been a national audit, CTs appear still to continue to carry out these tasks, though now in a bewildering array of organisational arrangements (Cambridge et al., 2005).

Without denying the barriers to full citizenship that still exist, much has changed, at least in England, for people with IDs since 2000 through legislation, policy and practice. Given the dominance in policy and practice of a model of CTs as multi-disciplinary (Care Quality Commission, 2015) and, increasingly, multi-agency, partnerships with the potential for promoting health and well-being and community inclusion, it is surprising that recent research on this topic in England, as elsewhere in the UK, has been limited. Moreover, where such research exists, it has focussed primarily on services to meet the needs of men and women with additional mental health and/or behavioural needs (e.g. Hassiotis, 2002; Hall et al., 2006; Samuels et al., 2007). With few exceptions (e.g. Cambridge et al., 2005; Farrington et al., 2015), little attention has been paid to any other aspect of CTs. In

This article is protected by copyright. All rights reserved. 
this paper, part of a series relating to the design and functioning of an ID service, which includes five locality-based specialist integrated CTs for adults in one English county, we report on the experiences of health (NHS) and care management (local authority) team members.

\section{The experiences of staff in services for adults with IDs}

There is now a substantial empirical literature relating to the self-reported experiences of staff supporting people with IDs (see Chung and Harding, 2009; Hatton et al., 2004; Kurz et al., 2014; Mitchell and Hastings, 2001; Mills and Rose, 2011; Mutkins et al., 2011; Skirrow and Hatton, 2008). This literature suggests strongly that (though c.f. Lunsky et al., 2014), in high income countries in different continents, negative experiences are endemic. The symptoms of such experiences have typically been conceptualised as 'burnout', that is, the feeling of physical, emotional and mental exhaustion and impaired interest in activities relating to service users (Skirrow and Hatton, 2007). Typically, burnout is measured by the Maslach Burnout Inventory (MBI, Maslach and Jackson, 1981) comprising three elements: Emotional Exhaustion, Personal Accomplishment, and Depersonalization.

However, the literature so far has focussed on the experiences of direct support workers (DSWs) and it may be unwise to assume that it is generalisable to members of community teams for adults with IDs. First, DSWs typically focus entirely on providing care in the 'home' of the person with ID; secondly, there are normally differences between the two groups in their qualifications and training, salaries, and employment conditions. Finally, while DSWs may need to engage with practitioners from a range of backgrounds (e.g. General Practitioners and other members of primary care teams, care managers monitoring and reviewing placements, and members of CTs), they normally work for a single social care provider rather than in multi-disciplinary, and often multi-agency (health and local authority) teams.

In CTs, tensions may arise between different disciplines and/or agencies when different 'communities of practice' (Lave and Wenger, 1991; Wenger, 2000; Eckert, 2006; Clark et al., 2015) within those teams present barriers to collaboration and the improvement of

This article is protected by copyright. All rights reserved. 
service user outcomes. The existence of such tensions at the personal, team, and/or organisational levels may affect the continuity of care for service users and those who support them. In contrast with CTs for people with IDs, where the issue has barely been examined, team functioning has been assessed in CTs for men and women with mental health problems or primary care teams. Where a quantitative approach has been taken, the self-report Team Climate Inventory (TCl, Anderson and West, 1998; Carpenter et al., 2003; Bower et al., 2003; Campbell et al., 2001) has most often been used. Normative data from a large number of community teams are available (Anderson and West, 1994), though none are from CTs for people with IDs.

While considerable attention has been paid to the relationship between organisational factors and the experiences of DSWs, with very few exceptions (for example, Debra Moore Associates, 2011), such measures focus on the extent to which a service is perceived as meeting its workers' needs, not those of its service users. Moreover, with the exception of Moore's measure, which, as far as we know, has not been used in any of the published academic literature, none has been used in CTs for people with IDs.

In contrast with the TCl's focus on teams, the Quality Improvement Implementation Survey (QIIS) focuses on the context within which such teams might operate (Quinn and Kimberly, 1984; Shortell et al., 1995; Shortell et al., 2000). The QIIS has two parts. The first was developed to assess the perceived culture of an organisation, defined in terms of the values, beliefs and norms that shape organisational behaviour (Quinn and Kimberly, 1984, Shortell et al., 1995). The second was developed to assess the extent to which that organisation is believed by staff to create, sustain and operationalise a vision that encourages team members, service users, and other stakeholders to initiate, contribute to, and participate in the implementation of quality improvement (Shortell et al., 1995).The measure was first developed in the USA to operationalise the goals of the Baldrige National Quality Programme (www.baldrigepe.org; see Shortell et al., 1995) in hospitals and subsequently used in multi-disciplinary health settings there (Berlowitz et al., 2003), and in Pakistan (Rabbani et al., 2009). As far as we are aware, the measure has not previously been used to assess community-based services for people with IDs. 
Here, we report on findings relating to self-reported personal well-being, team functioning, and perceived organisational culture and commitment to quality in the five community Teams in a county-wide service. The findings relate to a specific, multi-disciplinary and inter-agency service, working with both independent social care providers and a variety of other agencies, but, in part because of the neglect of CTs should be of broader relevance to the development of service provision and commissioning.

\section{Methods}

\section{Ethics}

Advice about ethics was sought from the R \& D Department of the relevant NHS Trust. The study was deemed to be a service evaluation, for which ethical approval was not required, provided all participants gave consent and their responses were anonymised. Permission to carry out the study was granted in writing by the relevant service managers.

\section{Context}

The five locality-based CTs formed part of a county-wide community-based service for adults with intellectual disabilities covering urban and rural areas, some of which experience significant deprivation in an ethnically diverse part of the East of England. While there were differences in their practices, all the Teams were multi-disciplinary and multi-agency, with (i) health care (NHS) providers (employed by the local mental health Trust) in arts therapies (art and music), clinical psychology, ID nursing, occupational therapy, psychiatry, and speech and language therapy; and (ii) care managers (some of whom were qualified social workers) commissioning and monitoring social care provision. The service also included administrators but, as a group, they had no contact with service users and their care-givers and did not attend clinical meetings; they are not considered further here. In each Team, a local authority Practice Manager managed all the health practitioners (except psychiatry) and care managers. These Practice Managers were, in turn, accountable to two senior managers, Locality Managers, each covering a part of the county. In turn, the Locality Managers reported to the Interim Head of Service.

\section{Measures:}

This article is protected by copyright. All rights reserved. 
Three different measures were used to examine CT members' experiences at three levels:

1. Personal well-being: the Maslach Burnout Inventory (MBI: Maslach et al.,1981) is generally recognised as the most valid and reliable indicator of the symptoms of occupational 'burnout' syndrome (Schaufeli et al. 1993, as cited in Fagin et al., 1996). It comprises three self-report scales: Emotional Exhaustion (EE): physical and emotional overextension and exhaustion; Depersonalisation (DP): an impaired commitment to service users (Depersonalisation) and/or to work activities (Cynicism); and Personal Accomplishment (PA): an impaired feeling of the importance of work activities or of a sense of work-related achievement (Maslach et al., 1996), Each of the 22 items is rated on a seven-point scale, indicating the frequency with which it is experienced (from 'never' to 'every day'). The three scales have acceptable psychometric properties in terms of factor structure, internal consistency (Cronbach's $\alpha$ : 0.71-0.90), test-retest reliability (0.80-0.82), convergent and discriminant validity (for details, see Maslach et al. 1996). Typically, burnout is characterised by high scores on EE and DP, and a low score on PA (Leiter, 1988; Prosser et al., 1999). For clarity, scoring was reversed for the PA scale, so that a higher score in this study indicated a poorer sense of Personal Accomplishment: we refer to the reversed subscale as Diminished Personal Accomplishment.

2. Team experience: the Team Climate Inventory (TCl: Anderson \& West, 1994). The TCI is another established self-report measure (Agrell and Gustafson, 1994; Burningham \& West, 1995; West and Anderson, 1996; Bain et al., 2000; Ragazzoni et al., 2002; West et al., 2003; Rose et al., 2006). It comprises four scales for respondents: Vision (V): the extent to which the team has a clear, negotiated, shared and attainable focus; Participative Safety (PS): influence over decision-making, information sharing, frequency of interaction, and psychological safety to allow the expression of new ideas; Task Orientation (TO): perceived team commitment to excellence; and Support for Innovation (SI), a predictor of team innovation and creativity (Anderson and West, 1994). These four scales have acceptable psychometric properties in terms of factor structure, internal consistency (Cronbach's $\alpha$ : 0.84 to 0.94 for the different scales), construct and predictive validity (see Anderson and West, 1994, for further details). In addition, there are six items to assess social and task aspects of social desirability. 
Overall, the measure has 44 items, each rated on a five-point scale from 1 (strongly disagree) to 5 (strongly agree). On each of the team-related scales, higher scores indicate more positive perceptions of the team. According to the Manual, the responses of those who score very highly (20 or more) on the Social Desirability scale should not be used (Anderson and West, 1994).

3. Organisational experience: the Quality Implementation Improvement Survey - II (QIIS-II; Shortell et al., 1995; Shortell et al., 2000) is less well-known in the UK than the other measures. It is grounded in organisational theory (Scott et al., 2003) and was developed -in a hospital context, but it is also reported to be suitable for a range of work environments (Shortell et al., 2000). The measure comprises two parts. Part 1 (Quinn and Kimberly, 1984; Shortell et al., 2000) focusses on the perceived organisational culture (or, more often, cultures, since it is rare for an organisation to have only a single culture). The QIIS-II comprises four descriptions in each of five sections Character, Managers, Cohesion, Emphases, and Rewards. Respondents are asked to allocate points across the descriptions in each section depending on the perceived similarity to their work environment. The distributions of these points (0-100, with a higher score indicating a more dominant culture), are used to characterise the environment in terms of four kinds of organizational culture: Group (emphasising affiliation, team working, and participation); Developmental (emphasising risk-taking, innovation and change); Hierarchical (emphasising rules, regulations, and reporting relationships); and Rational (emphasising efficiency and achievement).

With the exception of the Leadership section, Part 2 (Shortell et al., 1995; Shortell et al., 2000) relates to respondents' perception of their organisation's commitment to excellence in the quality of its performance in activities and functions involved in service users' treatment and support. In its standard form, this Part contains 78 statements across seven scales: Leadership, Information and Analysis , Strategic Quality Planning, Human Resource Utilization, Quality Management, Quality Results, and Service User Satisfaction, each of which has satisfactory internal consistency (Cronbach's a range: 0.79-0.93; Shortell et al., 2000). Each of the statements is accompanied by a five-point scale (from 1 (strongly agree) to 5 (strongly disagree) and an additional 'don't know' 
option), with a higher score in each section indicating a greater level of commitment to the service's quality.

Both Parts 1 and 2 were amended to make them more relevant to CTs: first, by replacing 'hospital' to 'Team' or 'my Team' throughout; and secondly, by repeating the Leadership subscale so that it could be used to assess perceptions of both Practice Managers (middle managers) and Locality Managers (senior managers). In this amended version, there were a total of 78 statements for all staff except Practice Managers: they were not asked to rate themselves ${ }^{1}$.

\section{Procedure}

Information sheets were distributed to each health care practitioner, care manager and Practice Manager in the five CTs. Those who wished to take part received a pack containing a booklet with a consent form, all three questionnaires and a stamped addressed envelope. The questionnaires took about 30 minutes to complete. The booklets were coded in advance so that the Team, area of practice, and role (Practice Manager or not) of the respondents could be identified, with the key to the code known only to the lead author. Completed booklets were returned to the research team's administrator, and the consent forms were removed and stored securely. The completed questionnaires, none of which were completed by any of the research team, were then scored and stored separately and securely. After data analysis, the findings (for the relevant CT and the service as a whole) were presented to each of the five CTs by members of the research team and the Head of Service, and their implications discussed. Subsequently, and regardless of whether or not they had chosen to take part, every CT member received a written summary from the lead author with the findings for their Team and information about sources of support in case of concerns about work-related or other stress. This was accompanied by recommendations drawing on the discussion with the CT members' specific Team.

\section{Scoring and analysis of the data}

The data were scored according to the guidance in the relevant manuals (Anderson and West, 1994; Maslach et al., 1996; Shortell et al., 1995). As noted, scoring was reversed 
for the Personal Accomplishment sub-scale of the $\mathrm{MBI}$, so that a higher score indicates a lower sense of Personal Accomplishment or Diminished Personal Accomplishment (DPA). Scores were analysed using SPSS (version 17.0), R (version 2.51.1). Since our primary focus of interest was the service comprising the five CTs, the results describe the overall findings for each measure. In addition, we investigated differences between healthcare practitioners (NHS) and care managers/Practice managers (LA). For the MBI, TCl and QIIS Part 2, we used an ANOVA (with a factor to adjust for the effect of team; interactions between staff group and team were explored but none were significant), with partial eta as a measure of effect size (approximately: small=0.01, medium $=0.09$ and large $=0.25$ ). Comparisons between staff group scores on Part 1 of the QIIS was not straightforward because of the ipsative nature of these data. Since the sample size was small we adopted a simplified approach: (i) calculate the mean distribution of culture points across culture types for each staff group (as in the bottom two rows of Table 3); (ii) round these to the nearest integer; and then (iii) treating as categorical data (see Table S1), using Fisher's exact test to examine statistically significant differences between the allocation of points to different cultures types by the two staff groups. Since there was multiple testing for differences between staff groups, Bonferroni's correction was used. Differences were judged to be significant if their associated $p$-values were smaller than $0.0029(\approx 0.05 / 17$, with the divisor of 17 since there were 16 comparisons on the ANOVAs $(3 \mathrm{MBI}, 5 \mathrm{TCl}, 8$ QIIS: Part 2) and one comparison on Fisher's exact test for the QIIS: Part 1 data.

\section{RESULTS}

\section{Demographics}

Of the 101 booklets sent out, almost three-quarters ( $N=73 ; 72 \%)$ were returned with all, or most, items completed. There was no significant difference between the proportion of returns from participants working in health care or care management (health care: $65 \%$, 36/55; care management: $80 \%, 37 / 46$; Fisher's exact test, $p=0.1197$ ). Health care staff were significantly more likely to have worked in the service for longer than care managers (Fisher's exact test, $\mathrm{p}=0.0029$ ).

\section{Performance on the measures}

This article is protected by copyright. All rights reserved. 
Table 1 shows the scores of the respondents on each of the MBI, TCI and QIIS Part 2 scales. For all scales the number of valid responses was fewer than 73 , because some items were returned incomplete and/or, on the $\mathrm{TCl}$, Social Desirability scores were greater than 20 (Anderson et al., 1994). To provide a context for the scores for the MBI scores, they were compared with the available normative data, with the categories relabelled 'good', 'acceptable' and 'of concern' rather than as 'high', 'average' or 'low'. For consistency, we have treated the 'high', 'middle' and 'low' scores on the $\mathrm{TCl}$ in the same way. In the absence of normative data for CTs for people with IDs, we have compared the scores with those of social services teams $(\mathrm{N}=42$; Anderson and West, 1994).

\section{INSERT TABLE 1 ABOUT HERE}

1. Personal well-being:

Table 1 shows that the scores on the MBI for Depersonalisation (mean=5.15, median=4, 'good' range: 0-6), Emotional Exhaustion (mean=22.39, median=21, 'acceptable'=17-26) and Diminished Personal Accomplishment (mean=13.52, median=13, 'acceptable=10-16). To provide more detail, the proportion of CT members whose scores fell into each of the 'good', 'acceptable' and 'of concern' categories was calculated. In contrast with Depersonalisation, on which almost three-quarters $(73 \%, 52 / 71)$ of respondents scored within the 'good' range, about a third of the sample obtained EE and/or DPA scores that were 'of concern' (EE: 35\%, 25/71; DPA: 37\%, 25/67). Of the 67 staff with valid responses across all three $\mathrm{MBI}$ scales, fewer than half (42\%; 28/67) had no scores within the 'of concern' range. A small proportion $(4 \%, 3 / 67)$ obtained scores that were 'of concern' on all three scales.

\section{Team experience}

Table 1 shows the scores on the TCI for Participative Safety (mean=39.92, median=41, 'acceptable' = 48-37), Support for Innovation: mean=22.70, median=24, 'acceptable'=2622), Task Orientation (mean=20.40, median=21, 'acceptable'=28-21, 'of concern'=20-7) and Vision ( $m e a n=28.52$, median=29, 'of concern'=33-11).

INSERT TABLE 2 ABOUT HERE

This article is protected by copyright. All rights reserved. 
The proportion of respondents whose scores fell into each of the 'good', 'acceptable' and 'of concern' categories on each of the scales was calculated, and is shown in Table 2. The TCl scores ( $\mathrm{N}=53$ for all scales) show that the largest proportion of staff scored in the 'acceptable' range on three of the scales (Participative Safety: 70\%, $n=44$; Support for Innovation: 44\%, n=28; Task Orientation: 56\%, n=35). With the exception of Support for Innovation, on which $21 \%$ (13) of scores were classifiable as 'good', the proportion of scores in the 'acceptable' range on the other scales was very low (PS: $6 \%, 4 / 63$; V: $2 \%$, 1/61; TO: $2 \%, 1 / 63)$. The scores on the Vision scale were particularly striking: almost four in five respondents' $(79 \%, 48 / 61)$ scores lay in range that 'of concern'. Very few respondents expanded upon their responses, but one CT member added a comment on the TCI response sheet: 'Vision? What vision?'

\section{Perceived commitment to quality}

Table 1 presents the descriptive statistics for the eight scales of the QIIS Part 2. The medians for all scales fell in the range 2.87-3.14, with a score of 3 corresponding to 'neither disagree nor agree').

\section{Perceived service culture}

Of the 73 returned QIIS Part 1 questionnaires, the overwhelming majority (97\%, 71/73) were valid. Table 3 shows the mean distribution of the 100 culture points across the different culture types for the service. Staff reports indicated a perception of the service as biased towards a hierarchical culture (allocated 35 points). Group and rational cultures were seen as equally important (26 points) while perception of a Developmental culture within the service were limited (13 points).

\section{INSERT TABLE 3 ABOUT HERE}

\section{Differences between health care and care management practitioners}

The results of statistical tests for differences in responses between health care and care management practitioners (having adjusted for differences between different CTs) on the MBI, TCl and QIIS Part 2 (Quality) scales are shown on the right of Table 1. Differences 
between the two groups of practitioners on the $\mathrm{MBI}$ and $\mathrm{TCl}$ were either non-significant $(p>0.07)$ or had very small effects (except for Depersonalisation, all partial etas $<0.01$ ). In terms of the QIIS Part I (Service Culture), there were no significant differences between the two groups (Fisher's exact test: $p=0.7921$ ): as shown in Table 3 , both scored Developmental and Rational culture types equally, though health care team members allocated more points than care managers to the Hierarchical culture type.

Larger, though still limited, differences were seen on the QIIS Part 2 scales. At the Bonferroni corrected significance level, two differences were found between the two areas of practice: on Employee Quality Training ( $p=0.00180$; partial eta=0.14), where care management practitioners were more positive (giving ratings that were on average higher by 0.7 than those of their health care colleagues) and on Information and Analysis $(p=0.00025$; partial eta=0.19), where care managers again were more positive (giving ratings that were on average 1.4 points higher than those of their health care respondents).

\section{DISCUSSION}

Specialist community teams for adults with intellectual disabilities are complex, involving both multi-disciplinary and, often, also multi-agency working, potentially engaging different 'communities of practice' (Lave and Wenger, 2001; Wenger, 2000; Eckert, 2006). Yet very little is known about any aspect of such teams. In this paper we have reported on psychological well-being and perceived team functioning, commitment to quality, and organisational culture in a county-wide intellectual disability service with five localitybased integrated Teams in order to inform the development of such services and their commissioning. Although there are limitations, given a small sample size, some missing responses, the use of self-report questionnaires, and in the case of the QIIS-II, a measure based on the contested concept of an 'organisation' (Thompson and Rose, 2011) and with incomplete psychometric properties, the study is innovative in two ways. First, it has focused specifically on the work of the specialist practitioners who make up the community teams, rather than on the single discipline of direct support workers working 
for an independent provider, and secondly, by using three different measures in one study, we have considered these practitioners as members of an organisation rather than simply as individuals working independently. CTs not only need to bring together the skills of different disciplines, and often different agencies, to benefit service users with IDs and their families, but also work with a range of independent social care providers. The task is very complex and brings with it the potential for clashes in organisational practices.

The findings relating to psychological well-being suggested that the individual functioning of both health care and care management practitioners was reasonable. There was limited evidence among CT members of the cynicism towards service users and/or work activities that is reflected in high Depersonalisation scores. Nevertheless, and consistent with the high level of 'burnout' both among direct support workers in services for people with IDs (Hatton et al., 2004; Skirrow and Hatton, 2007), and among 'human services' workers generally (Maslach et al., 1996), more than half the respondents (57\%) obtained $\mathrm{MBI}$ scores on one or more scales that were 'of concern', with the scores of a small proportion $(3 / 67,4 \%)$ of respondents falling into this category on all three scales. While only scores on the Emotional Exhaustion sub-scale have been linked to job performance (Taris, 2006), the findings suggested that both health care practitioners and care managers would benefit from support to maintain and promote their well-being. Clinical and line-management supervision are not the only ways through which this could be provided. Support could also be provided through interactions with team colleagues and, particularly, through team meetings, which offer opportunities for sharing risk, constructive reflection, and a strengthened sense of purpose. However, the perception of the availability of such support was not encouraging, even when comparing the scores with those of a group of social services teams whose work is likely to be more stressful (Gibson et al., 1989; Schraer, 2015).

Combining $\mathrm{TCl}$ responses in the 'good' and 'acceptable' ranges, the most encouraging scores were on the Participative Safety $(76 \%, N=63)$ and Support for Innovation (61\%, $\mathrm{N}=63$ ) scales. With regard to Participative Safety, the findings suggested that around three quarters of the respondents perceived that they had an influence over decisionmaking and that it was 'safe' to express ideas. Moreover, consistent with the results of a 
qualitative study of two of the Teams by Farrington et al. (2015), the scores indicated frequent interaction and information sharing at 'ground' level. Similarly, the scores of approaching two-thirds of the respondents indicated that novel and creative approaches were supported. These findings do not suggest that the Teams are perceived as toxic places to work. Yet, in contrast to the 'support for innovation' sub-scale, only one respondent's score on 'Task Orientation', which reflects the perceived commitment to excellence, fell into the 'good' range; the scores of the remaining sixty respondents were 'acceptable' and, for more than four in ten respondents, were 'of concern'. The findings relating to 'Vision' were also of note: the scores of more than three-quarters of the respondents suggested that they were concerned about the absence of a clear, negotiated, shared and attainable focus in their team. Taken together, these findings suggest that the Teams may provide psychological support, but that they do not generate that strong sense of purpose that would provide a context for a commitment to quality. While the normative data available for Part 2 of the QIIS-II are limited (Shortell et al., 2000), the median scores of 'neither disagree nor agree' across all eight dimensions were consistent with this account.

Supporting Team members' perception of a lack of vision in the service, the findings from the Leadership scales of Part 2 of the QIIS-II (Shortell et al., 1995, 2000) suggested limited confidence in the leadership provided by middle managers at both a team and a locality level. It is possible that such feelings were exacerbated by the culture of the service, which was managed by the local authority, with its traditionally 'top-down' culture (Megele, 2012) and 'managerialist' (Clarke et al. 2000) tendencies. Of the four types of cultures identified by Shortell et al. (1995) to function effectively, a primarily hierarchical culture with a strong focus on bureaucracy and process, notwithstanding a good deal of positive interaction at 'ground' level (Farrington et al., 2015), is at odds with what has been shown empirically (Shortell et al., 1995) to be the environment in which a commitment to excellent quality is most likely to thrive. Health care practitioners were more likely to perceive the culture as less sympathetic than their care management colleagues, allocating proportionately fewer points to a 'group' and more to a 'hierarchical' culture type. This may be explained by the fact that health care practitioners were more likely to have worked in the service for longer and therefore to have experienced the light 
touch' of the mental health Trust that managed the health care Teams prior to integration. Moreover, practitioners in the two areas of work come from different 'communities of practice' and have different cultures (proportionately fewer points allocated to 'group' and more to 'hierarchical') than their local authority colleagues. On all other measures, and in other parts of the QIIS-II, the responses of the two professional groups were very similar, with two exceptions: care managers rated 'information and analysis' (relating to the collection and use of relevant data) and 'quality management training' (related to the development of skills in job performance') significantly more positively than their health care colleagues. A possible explanation lies in the local authority's management of the service: it might be expected that its data collection and training would focus on the needs of its own workers. In contrast, health care practitioners often reported that the local authority had limited understanding of their training, supervision, and appraisal needs. Supporting this account, in two of the five team bases, which were located in local authority facilities, health care practitioners had no access to the mental health Trust's website and widely reported that they felt isolated from the professional development opportunities available to their health care colleagues working elsewhere (Farrington et al., 2015),

Local factors at the time of the study, particularly relating to the absence of a permanent head of service and service restructuring, may have affected the findings. Investigating the impact of such local changes would require a more sophisticated project, perhaps using a longitudinal design, to be carried out. Certainly, a larger sample size would have permitted more sophisticated analysis such as the use of structural equation modelling of the relationships between the three quantitative measures and enabled us to compare the responses on the measures of individuals in different professions with a large range of covariates associated with distress or discontent and the relationships between them (see Hatton et al., 2004; Mutkins et al., 2011; Skirrow and Hatton, 2007). Such research was beyond the scope of the present study.

Rather, the intention here was to use the example of a county-wide integrated localitybased specialist service for adults with intellectual disabilities, comprising five different Teams carrying out similar work and all managed by the local authority, to start to 
reinvigorate research on the CTs that play a crucial role in supporting people with IDs to live 'ordinary lives' in community settings. From this perspective, the most important finding is that a perceived lack of vision permeated the service, potentially compromising its capacity to be proactive rather than simply to react to immediate events. How might this best be addressed in the future? We believe that it would be timely to revisit the tasks identified by Lindsey (2002) in light of the changes in legislation, policy and practice that have taken place since 2000 , and, in particular, the challenges of the forthcoming reductions in the number of new 'out-of-area' hospital beds for people with IDs and additional mental health and/or behavioural needs (NHS England, 2015). We propose that the main implications of this research are: first, a service that is multi-disciplinary and inter-agency must have an agreed vision so that CT members are clear in their own minds as to their purpose of the Team. What is the role of a CT within the wider context of primary and secondary healthcare and generic local authority services available to the population as a whole? Secondly, team cohesion is critically important and this may be best maintained through regular CT meetings with the sharing of ideas and managing concerns about risk. Thirdly, there must be an explicit understanding from senior management that, whilst there will be many needs that care managers and health practitioners share in common, there will also be differences with respect to working practices, appraisal, record-keeping, and training needs. These must be fully recognised and accommodated. Future research could usefully focus on the evaluation of service interventions that address these specific issues. Through the development of such an evidence base, service commissioners could be much clearer about their expectations of specialist teams in working alongside people with ID, their families, social care providers and other agencies.

This article is protected by copyright. All rights reserved. 


\section{NOTE}

${ }^{1}$ The amended versions of the Quality Implementation Improvement Survey - II (QIIS-II, Shortell et al., 1995, 2000) are available from the first author.

\section{ACKNOWLEDGEMENTS}

To be completed. Will include information on funding for the study.

\section{REFERENCES}

Agrell, A. \& Gustafson, R. (1994). The Team Climate Inventory (TCl) and group innovation: A psychometric test on a Swedish sample of work groups. Journal of Occupational and Organizational Psychology, 67(2), 143-151.

Anderson, N. \& West, M.A. (1994). Team Climate Inventory: Manual and User's Guide. Windsor, UK: NFER-Nelson.

Anderson, N. R. \& West, M.A. (1998). Measuring climate for work group innovation: Development and validation of the Team Climate Inventory. Journal of Organisational Behaviour, 19 (3), 235-258.

Bain, P. G., Mann, L. \& Pirola-Merlo, A. (2001). The innovation imperative the relationships between team climate, innovation, and performance in research and development teams. Small Group Research, 32(1), 55-73.

Berlowitz, D.R., Young, G.J., Hickey, E.C., Saliba, D., Mittman, B.S., Czarnowski, E., et al. (2003). Quality improvement implementation in the nursing home. Health Service Research, 38 (1), 65-83.

This article is protected by copyright. All rights reserved. 
Bower, P., Campbell, S., Bojke, C., \& Sibbald, B. (2003). Team structure, team climate and the quality of care in primary care: an observational study. Quality and Safety in Health Care, 12(4), 273-279.

Burningham, C. \& West, M. A. (1995). Individual, climate, and group interaction processes as predictors of work team innovation. Small Group Research, 26(1), 106-117.

Cambridge, P., Carpenter, J., Forrester-Jones, R., Tate, A., Knapp, M., Beecham, J., et al. (2005). The state of care management in learning disability and mental health services 12 years into community care. British Journal of Social Work, 35, 1039-1062.

Campbell, S. M., Hann, M., Hacker, J., Burns, C., Oliver, D., Thapar, A., et al. (2001). Identifying predictors of high quality care in English general practice: Observational study. British Medical Journal, 323(7316), 784.

Care Quality Commission (2015). Community Learning Disability Services. [Online]. Available at: http:// www.cqc.org.uk/content/community [Accessed 4th November 2015].

Carpenter, J., Schneider, J., Brandon, T., \& Wooff, D. (2003). Working in multidisciplinary community mental health teams: The impact on social workers and health professionals of integrated mental health care. The British Journal of Social Work, 1081-1103.

Clark, M., Cornes, M., Manthorpe, J., Hennessy, C. \& Anderson, S (2015). Releasing the grip of managerial domination, Journal of Integrated Care, 23(5), 287-301.

Clarke, J., Gerwitz, S. and McLaughlin, E. (2000). Reinventing the welfare state, in Eds. J. Clarke, S. Gerwitz, and E. McLaughlin. New Managerialism, New Welfare? London: Open University in association with SAGE Publications Ltd., 1-26.

Debra Moore Associates (2011) Confirm \& Challenge. [Online] Available at: http://www.debramooreassociates.com [Accessed $19^{\text {th }}$ November 2015].

Chung, M. C., \& Harding, C. (2009). Investigating burnout and psychological well-being of staff working with people with intellectual disabilities and challenging behaviour: the role of personality. Journal of Applied Research in Intellectual Disabilities, 22(6), 549-560.

This article is protected by copyright. All rights reserved. 
Eckert, P. (2006). Communities of practice. Encyclopedia of language and linguistics $2^{\text {nd }}$ ed., Oxford: Elsevier, 683-685.

Fagin, L., Carson, J., Leary, J., De Villiers, N., Bartlett, H., O'Malley, P., et al. (1996). Stress, coping and burnout in mental health nurses: findings from three research studies. International Journal of Social Psychiatry, 42(2), 102-111.

Farrington, C. [Citation removed to maintain anonymity for review]

Gibson, F., McGrath, A. \& Reid, N. (1989). Occupational stress in social work, British Journal of Social Work, 19, 1-16.

Greig, R. \& Peck, E. (1998). Is there a future for the community learning disabilities team? Tizard Learning Disability Review, 3(1), 35-41.

Hall, I., Parkes, C., Samuels, S., \& Hassiotis, A. (2006). Working across boundaries: clinical outcomes for an integrated mental health service for people with intellectual disabilities. Journal of Intellectual Disability Research, 50(8), 598-607.

Hassiotis, A. (2002). Community mental health services for individuals with intellectual disabilities. Disease Management \& Health Outcomes, 10(7), 409-417.

Hatton, C., Rose, J., \& Rose, D. (2004). Researching staff. The International Handbook of Applied Research in Intellectual Disabilities, 581-605.

Kurz, A. S., Bethay, J. S. \& Ladner-Graham, J. M. (2014). Mediating the relation between workplace stressors and distress in ID support staff: Comparison between the roles of psychological inflexibility and coping styles. Research in Developmental Disabilities, 35(10), 2359-2370.

Lave, J. \& Wenger, E. (1991) Situated Learning: Legitimate Peripheral Participation. Cambridge: Cambridge University Press.

Leiter, M. P. (1988). Burnout as a function of communication patterns. A study of a multidisciplinary mental health team. Group \& Organization Management,3(1), 111-128.

This article is protected by copyright. All rights reserved. 
Lindsey, M. (2002). Comprehensive health care services for people with learning disabilities, Advances in Psychiatric Treatment, 8, 138-148.

Lunsky, Y., Hastings, R. P., Hensel, J., Arenovich, T. \& Dewa, C. S. (2014). Perceptions of positive contributions and burnout in community developmental disability workers. Intellectual and Developmental Disabilities, 52(4), 249-257.

Maslach, C. \& Jackson, S. E. (1981). The measurement of experienced burnout. Journal of Occupational Behaviour, 2, 99-113.

Maslach, C., Jackson, S.E. \& Leiter, M.P. (1996). Maslach Burnout Inventory Manual (3 ${ }^{\text {rd }}$ ed). Palo Alto, CA: Consulting Psychologist Press.

Megele, C. (2012) Social care in the e-professionalism era, The Guardian. [Online] Available at: http://www.theguardian.com/social-carenetwork/2012/apr/25/eprofessionalism-social-care [Accessed $30^{\text {th }}$ October 2015].

Mills, S. \& Rose, J. (2011). The relationship between challenging behaviour, burnout and cognitive variables in staff working with people who have intellectual disabilities. Journal of Intellectual Disability Research, 55(9), 844-857.

Mitchell, G. \& Hastings, R. P. (2001). Coping, burnout, and emotion in staff working in community services for people with challenging behaviours. American Journal on Mental Retardation, 106(5), 448-459.

Mutkins, E., Brown, R. F. \& Thorsteinsson, E. B. (2011). Stress, depression, workplace and social supports and burnout in intellectual disability support staff. Journal of Intellectual Disability Research, 55(5), 500-510.

Prosser, D., Johnson, S., Kuipers, E., Dunn, G., Szmukler, G., Reid, Y., et al. (1999). Mental health,"burnout" and job satisfaction in a longitudinal study of mental health staff. Social Psychiatry and Psychiatric Epidemiology, 34(6), 295-300.

Quinn, R. E., \& Kimberly, J. R. (1984). Paradox, planning, and perseverance: Guidelines for managerial practice. Managing organizational transitions. Homewood, IL: R.D. Irwin, 295-313.

This article is protected by copyright. All rights reserved. 
R Core Team (2012). R: A Language and Environment for Statistical Computing. Vienna, Austria: R Foundation for Statistical Computing. [Online]. Available at: http://www.Rproject.org

Rabbani, F., Jafri, S.M.W., Abbas, F., Jahan, F., Syed, N.A., Pappas, G., et al. (2009). Culture and quality care perceptions in a Pakistani hospital. International Journal of Health Care Quality Assurance, 22(5), 498-513.

Ragazzoni, P., Baiardi, P., Zotti, A. M., Anderson, N., \& West, M. (2002). Research note: Italian validation of the team climate inventory: a measure of team climate for innovation. Journal of Managerial Psychology, 17(4), 325-336.

Rose, J., Ahuja, A. K., \& Jones, C. (2006). Attitudes of direct care staff towards external professionals, team climate and psychological wellbeing: A pilot study. Journal of Intellectual Disabilities, 10(2), 105-120.

Samuels, S., Hall, I., Parkes, C., \& Hassiotis, A. (2007). Professional staff and carers' views of an integrated mental health service for adults with learning disabilities. The Psychiatrist, 31(1), 13-16.

Schraer, R. (2015). Social workers too stressed to do their job according to survey. Community Care, $7^{\text {th }}$ January. [Online]. Available at: http:// www.communitycare.co.uk/2015/01/07/stress-stopping-job-social-workers-say [Accessed $1^{\text {st }}$ December, 2015]

Scott, T., Mannion, R., Davies, H., \& Marshall, M. (2003). The quantitative measurement of organizational culture in health care: a review of the available instruments. Health services research, 38(3), 923-945.

Skirrow, P., \& Hatton, C. (2007). 'Burnout' amongst direct care workers in services for adults with intellectual disabilities: a systematic review of research findings and initial normative data. Journal of Applied Research in Intellectual Disabilities, 20(2), 131-144.

Shortell, S.M., O'Brien, J.L., Carman, J.M., Foster, R.W., Hughes, E.F.X., Boerstler, H., et al. (1995). Assessing the impact of continuous quality management/total quality

This article is protected by copyright. All rights reserved. 
management: Concept versus implementation. Health Services Research, 30(2), 377401.

Shortell, S. M., Jones, R. H., Rademaker, A. W., Gillies, R. R., Dranove, D. S., Hughes, E. F. et al. (2000). Assessing the impact of total quality management and organizational culture on multiple outcomes of care for coronary artery bypass graft surgery patients. Medical Care, 38(2), 207-217.

SPSS Inc (2008) SPSS Statistics for Windows, Version 17.0. Chicago: SPSS Inc.

Taris, T. W. (2006). Is there a relationship between burnout and objective performance? A critical review of 16 studies. Work \& Stress, 20(4), 316-334.

Thompson, L. \& Rose, J. (2011). Does organizational climate impact upon burnout in staff who work with people with intellectual disabilities? A systematic review of the literature. Journal of Intellectual Disabilities, 15(3), 177-193.

Wenger, E. (2000). Communities of practice and social learning systems. Organization, 7(2), 225-246.

West, M. A., \& Anderson, N. R. (1996). Innovation in top management teams. Journal of Applied Psychology, 81(6), 680.

West, M. A., Borrill, C. S., Dawson, J. F., Brodbeck, F., Shapiro, D. A., \& Haward, B. (2003). Leadership clarity and team innovation in health care. The Leadership Quarterly, 14(4), 393-410.

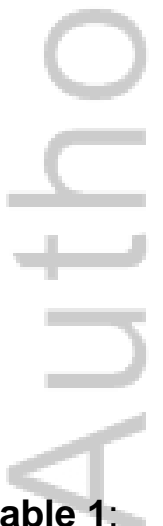

This article is protected by copyright. All rights reserved. 
Descriptive statistics for the scales of a) the Maslach Burnout Inventory (MBI); b) Team Climate Inventory (TCI); and c) the Quality Improvement Implementation Survey, Part 2 (QIIS -2), and for the comparisons on each scale between health care and care management $\mathrm{CT}$ members ( $\mathrm{N}=73$ returned forms)

\section{Table 2:}

The distribution of scores on each scale of the Maslach Burnout Inventory (compared with those of 11,000 human services workers, Maslach et al., 1996 ) and Team Climate Inventory (42 social services teams, Anderson and West, 1994) ( $\mathrm{N}=73$ returned forms).

Table 3:

Means and standard deviations of the points allocated to each of four culture types (Shortell et al., 1995) for: i) the whole service; ii) for health care and care management CT members separately ( $\mathrm{N}=73$ returned forms).

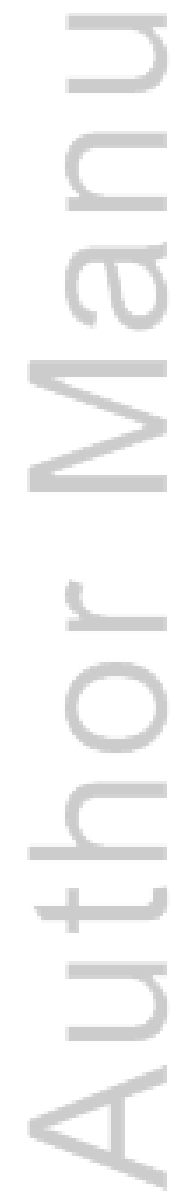

This article is protected by copyright. All rights reserved. 
Table 1

\begin{tabular}{|c|c|c|c|c|c|c|c|c|c|c|}
\hline \multirow{4}{*}{ 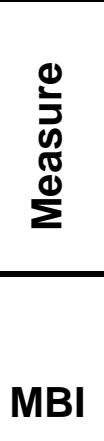 } & \multirow{3}{*}{$\begin{array}{l}\frac{0}{\mathbb{J}} \\
\text { ஸ } \\
\begin{array}{l}\text { Emotional } \\
\text { exhaustion }\end{array} \\
\end{array}$} & \multirow{3}{*}{$\begin{array}{l}\frac{.0}{7} \\
71\end{array}$} & \multirow{3}{*}{$\begin{array}{l}\frac{\text { 음 }}{\text { Ð }} \\
2\end{array}$} & \multirow{3}{*}{ 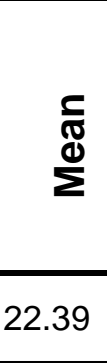 } & \multirow{3}{*}{$\begin{array}{l}\frac{\frac{\sigma}{\sigma}}{0} \\
\frac{0}{0} \\
21\end{array}$} & \multirow{2}{*}{\multicolumn{2}{|c|}{$\begin{array}{l}95 \% \\
\text { confidence } \\
\text { interval }\end{array}$}} & \multicolumn{3}{|c|}{$\begin{array}{c}\text { Differences between health } \\
\text { care and care management } \\
\text { CT members* }\end{array}$} \\
\hline & & & & & & & & F-stat & $\mathrm{P}$ & $\begin{array}{l}\text { Partial } \\
\text { Eta }\end{array}$ \\
\hline & & & & & & 19.67 & 25.12 & $F(1,65)=0.38$ & 0.540 & 0.01 \\
\hline & & 71 & 2 & 5.15 & 4 & 3.94 & 6.37 & $F(1,65)=3.45$ & 0.068 & 0.05 \\
\hline & $\begin{array}{l}\text { Diminished personal } \\
\text { accomplishment }{ }^{\star \star}\end{array}$ & 67 & 6 & 13.52 & 13 & 11.99 & 15.05 & $F(1,61)=0.30$ & 0.584 & $<0.01$ \\
\hline \multirow{5}{*}{$\mathrm{TCl}$} & Participative safety & 63 & 10 & 39.92 & 41 & 37.86 & 41.98 & $F(1,57)<0.01$ & 0.958 & $<0.01$ \\
\hline & $\begin{array}{l}\text { Support for } \\
\text { innovation }\end{array}$ & 63 & 10 & 22.70 & 24 & 21.31 & 24.09 & $F(1,57)=0.11$ & 0.743 & $<0.01$ \\
\hline & Vision & 61 & 12 & 28.52 & 29 & 26.39 & 30.66 & $F(1,55)=0.07$ & 0.791 & $<0.01$ \\
\hline & Task orientation & 63 & 10 & 20.40 & 21 & 19.16 & 21.64 & $F(1,57)=0.02$ & 0.900 & $<0.01$ \\
\hline & 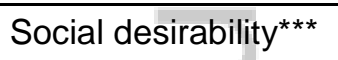 & 63 & 10 & 14.56 & 15 & 13.66 & 15.46 & $F(1,57)=0.18$ & 0.672 & $<0.01$ \\
\hline \multirow{6}{*}{$\begin{array}{l}\text { QIIS } \\
\text { Part } \\
2\end{array}$} & $\begin{array}{l}\text { Leadership: Locality } \\
\text { Manager }\end{array}$ & 64 & 9 & 2.71 & 2.87 & 2.49 & 2.94 & $F(1,58)=2.47$ & 0.122 & 0.04 \\
\hline & $\begin{array}{l}\text { Leadership: Practice } \\
\text { manager }\end{array}$ & 67 & 6 & 2.93 & 3.00 & 2.73 & 3.14 & $F(1,61)=3.19$ & 0.079 & 0.05 \\
\hline & $\begin{array}{l}\text { Information and } \\
\text { analysis }\end{array}$ & 69 & 4 & 2.92 & 3.00 & 2.71 & 3.13 & $F(1,63)=15.12$ & $\begin{array}{c}<0.0002 \\
\star \star \star \star \star \\
\end{array}$ & 0.19 \\
\hline & Quality management & 69 & 4 & 3.07 & 3.14 & 2.88 & 3.25 & $F(1,63)=3.29$ & 0.075 & 0.05 \\
\hline & $\begin{array}{l}\text { Quality } \\
\text { results }\end{array}$ & 69 & 4 & 3.07 & 3.14 & 2.88 & 3.25 & $F(1,63)=3.29$ & 0.075 & 0.05 \\
\hline & $\begin{array}{l}\text { Service user } \\
\text { satisfaction }\end{array}$ & 70 & 3 & 2.99 & 3.00 & 2.78 & 3.21 & $F(1,64)=1.83$ & 0.181 & 0.03 \\
\hline
\end{tabular}

* Having adjusted for differences between Teams.

** Lower scores indicate greater well-being.

*** Higher scores indicate greater social desirability.

$\star \star \star \star \quad \rho$ values given to greater precision to facilitate comparison with Bonferroni

corrected level of significance (0.0029)

This article is protected by copyright. All rights reserved. 
Table 2

\begin{tabular}{|c|c|c|c|c|c|c|c|c|c|c|c|}
\hline \multirow[b]{2}{*}{ 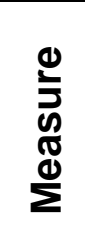 } & \multirow[b]{2}{*}{$\frac{0}{\pi}$} & \multirow[b]{2}{*}{ 음 } & \multicolumn{3}{|c|}{ 'Good' } & \multicolumn{3}{|c|}{ 'Acceptable' } & \multicolumn{3}{|c|}{ 'Of concern' } \\
\hline & & & 䓂 & $\%$ & 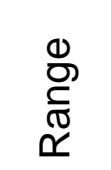 & 䓂 & $\%$ & $\begin{array}{l}\stackrel{0}{\mathscr{g}} \\
\stackrel{\sigma}{\sigma} \\
\widetilde{1}\end{array}$ & 蒙 & $\%$ & 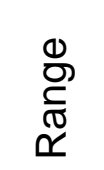 \\
\hline \multirow{3}{*}{ MBI } & $\begin{array}{l}\text { Emotional } \\
\text { exhaustion }\end{array}$ & 71 & 28 & $39 \%$ & $0-16$ & 18 & $25 \%$ & $17-26$ & 25 & $35 \%$ & $27-54$ \\
\hline & Depersonalisation & 71 & 52 & $73 \%$ & $0-6$ & 14 & $20 \%$ & $7-12$ & 5 & $7 \%$ & $13-30$ \\
\hline & $\begin{array}{l}\text { Diminished } \\
\text { personal } \\
\text { accomplishment }\end{array}$ & 67 & 20 & $30 \%$ & $0-9$ & 22 & $33 \%$ & $10-16$ & 25 & $37 \%$ & $17-48$ \\
\hline \multirow{4}{*}{$\mathrm{TCl}$} & $\begin{array}{l}\text { Participative } \\
\text { safety }\end{array}$ & 63 & 4 & $6 \%$ & $60-49$ & 44 & $70 \%$ & $48-37$ & 15 & $24 \%$ & $36-12$ \\
\hline & $\begin{array}{l}\text { Support for } \\
\text { innovation }\end{array}$ & 63 & 13 & $21 \%$ & $40-27$ & 28 & $44 \%$ & $26-22$ & 22 & $35 \%$ & $21-8$ \\
\hline & Vision & 61 & 1 & $2 \%$ & $55-45$ & 12 & $20 \%$ & $44-34$ & 48 & $79 \%$ & $33-11$ \\
\hline & Task orientation & 63 & 1 & $2 \%$ & $35-29$ & 35 & $56 \%$ & $28-21$ & 27 & $43 \%$ & $20-7$ \\
\hline
\end{tabular}

This article is protected by copyright. All rights reserved. 
Table 3

\begin{tabular}{|c|c|c|c|c|c|c|c|c|c|c|}
\hline \multirow[b]{3}{*}{ Group } & \multirow[b]{3}{*}{$\mathbf{N}$} & \multirow[b]{3}{*}{ Valid } & \multicolumn{8}{|c|}{ Culture } \\
\hline & & & \multicolumn{2}{|c|}{ Developmental } & \multicolumn{2}{|c|}{ Group } & \multicolumn{2}{|c|}{ Hierarchical } & \multicolumn{2}{|c|}{ Rational } \\
\hline & & & Mean & SD & Mean & SD & Mean & SD & Mean & SD \\
\hline $\begin{array}{l}\text { All CT } \\
\text { members }\end{array}$ & 73 & 71 & 13.0 & 8.8 & 25.9 & 17.8 & 35.1 & 19.1 & 26.0 & 12.2 \\
\hline Health care & 36 & 35 & 13.3 & 9.8 & 22.8 & 14.4 & 37.6 & 22.6 & 26.3 & 12.9 \\
\hline $\begin{array}{l}\text { Care } \\
\text { management }\end{array}$ & 37 & 36 & 12.7 & 7.8 & 29.0 & 20.3 & 32.6 & 14.8 & 25.7 & 11.7 \\
\hline
\end{tabular}

This article is protected by copyright. All rights reserved. 


\section{University Library}

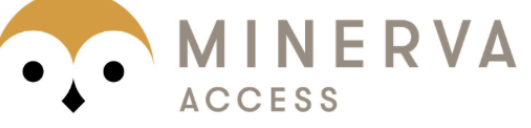

A gateway to Melbourne's research publications

Minerva Access is the Institutional Repository of The University of Melbourne

\section{Author/s:}

Clare, ICH;Madden, EM;Holland, AJ;Farrington, CJT;Whitson, S;Broughton, S;Lillywhite, A;Jones, E;Wade, KA;Redley, M;Wagner, AP

Title:

'What vision?': experiences of Team members in a community service for adults with intellectual disabilities.

Date:

2017-03

Citation:

Clare, I. C. H., Madden, E. M., Holland, A. J., Farrington, C. J. T., Whitson, S., Broughton, S., Lillywhite, A., Jones, E., Wade, K. A., Redley, M. \& Wagner, A. P. (2017). 'What vision?': experiences of Team members in a community service for adults with intellectual disabilities.. J Intellect Disabil Res, 61 (3), pp.197-209. https://doi.org/10.1111/jir.12312.

Persistent Link:

http://hdl.handle.net/11343/291684 